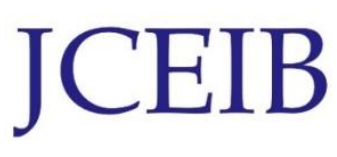

Journal Chemical Engineering and Industrial Biotechnology (JCEIB)

Open Access

Volume 3 pp. 17-25; March 2018

(CUniversiti Malaysia Pahang Publisher

DOI: https://doi.org/10.15282/JCEIB-V3-03.28/3/2018/3.3

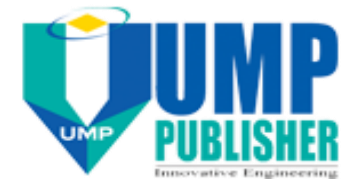

\title{
APPLICATION OF THERMODYNAMIC MODELLING AND EXPERIMENTAL INVESTIGATION OF LEACHING YTTRIUM FROM LIQUID CRYSTAL DISPLAY
}

\author{
Farouq Ahmat ${ }^{\mathrm{a}^{*}}$, Mohd Yusri Mohd Yunus ${ }^{\mathrm{a}}$, Badrulhisyam Abd Aziz ${ }^{\mathrm{a}}$, \\ Anwarrudin Hisyam ${ }^{\text {a }}$ \\ ${ }^{a}$ Faculty of Chemical and Natural Resources Engineering \\ Universiti Malaysia Pahang, Lebuhraya Tun Razak, \\ 26300, Gambang, Kuantan, Pahang Darul Makmur \\ * Corresponding author: E-mail: farouq_ahmat@yahoo.com \\ Tel.: +6014-7380950
}

\begin{abstract}
Thermodynamic modelling, experiment, measurement, and characterization technique were used to evaluate the leaching process of yttrium (Y) elements from liquid crystal display (LCD) electronic waste (e-waste). Thermodynamic modelling using HSC 6.0 software revealed that the reaction of leaching out $\mathrm{Y}$ with hydrochloric acid is endothermic thus absorbing heat and at the same time positive Gibbs free energy from temperature $273.15 \mathrm{~K}$ to $343.15 \mathrm{~K}$ and negative Gibbs free energy from temperature $353.15 \mathrm{~K}$ to $373.15 \mathrm{~K}$. Thermodynamic data of the leaching processes with sulfuric and nitric acids show that the reactions are exothermic thus release heat and the same time negative Gibbs free energy from temperature $273.15 \mathrm{~K}$ and above. The leaching reaction with sulfuric and nitric acids identified to be reversible from temperature $273.15 \mathrm{~K}$ and above due to the negative entropy change, whereas the reaction was found irreversible for the hydrochloric acid solution due to the positive entropy change at the similar minimum temperature setting. The significance of reversibility versus irreversibility is their relationship to the efficiency. The equilibrium constant show that the leaching process with hydrochloric acid is less than $1(\log \mathrm{K}<1)$ from temperature $273.15 \mathrm{~K}$ to $343.15 \mathrm{~K}$ indicate that the backward reaction is favored while from temperature 353.15 $\mathrm{K}$ to $373.15 \mathrm{~K}$ have a positive equilibrium constant $(\log \mathrm{K}>1)$ thus indicate that forward reaction is favored. Leaching process with sulfuric and nitric acids shows that the positive equilibrium constant $(\log K>1)$ which indicate that forward reaction is favored from temperature $273.15 \mathrm{~K}$ and above. The Pourbaix diagram modelling showed that $\mathrm{Y}$ dissolved in $\mathrm{HCl}$ at $\mathrm{pH}$ below 7 therefore strong reducing agents such as sulfuric acid (sulfide) can improve the dissolution of Y. Inductively coupled plasma mass spectroscopy (ICP-MS) results showed that only $\mathrm{Y}$ is viable to be efficiently leached from the studied LCD, e-waste either in a single-stage or in two-stage leaching mode. Sulfuric and nitric acids are found to be the most practical solutions in leaching out the Y element whereby around $0.00515 \mathrm{ppm}$ and $0.00507 \mathrm{ppm}$ of Y were dissolved in both solutions respectively based on the two-stages leaching approach.
\end{abstract}

Keywords: Yttrium; Liquid Crystal Display, Leaching, Modelling, Spectroscopy. 


\subsection{INTRODUCTION}

Rare earth elements (REEs) exist naturally in a small quantity either as an oxide or as a compound with other elements. REEs applications are ranging from the catalyst, pigment manufacturing and electronic components (Vijayalakshmi et al. 2001). REEs have been special interest in the industry due to the China monopoly on the rare earth global supplies. Most of the REEs are mined in China, United State, and Australia. China's rare earth reserve approximately $23 \%$ of the world's reserve and currently about $95 \%$ of world's rare earth metal mining and oxide production are from China (Paulick \& Machacek 2017). According to the survey done until 2011, REEs recycles is less than $1 \%$ of worldwide production (Haque et al. 2014). This limitation is mainly contributed by various factors, including inefficient collection, hazardous waste and technological barrier (Binnemans et al. 2013). Currently, REEs recycles only conducted at small laboratory scale but show no economic value at industrial scale due to inefficient recovery. Recycle sources are primarily coming from e-waste such as the computer, mobile phone, television, fluorescent lamp, magnet and battery (Schulze \& Bucharest 2016). REEs recycle from the fluorescent lamp and cathode ray tube (CRT) have been achieved recently, but none of the liquid crystal display (LCD) is reported (Park \& Rhee 2016). The development of Sepsalsa and La-Rochelle processes enable recovery of REEs from fluorescent lamp (Eduafo 2016). One of untapped recycle resource is an LCD that contains a series of REE, which utilized color phosphors. REEs mainly found in the LCD are yttrium, terbium, and europium. Yttrium (Y) possesses chemical properties almost similar to the lanthanides and mainly found from most of the rare earth minerals, but it does not exist as a free element. Y commonly extracted from minerals such as bastnasite, monazite, and xenotime (Deqian 2017). Xenotime contains around $60 \%$ of yttrium phosphate $\left(\mathrm{YPO}_{4}\right)$ while monazite and bastnasite sand contain approximately of $3 \%$ and $0.2 \%$ Y respectively (Gupta \& Krishnamurthy 2005).

The extraction method for Y from the ore mineral has been developed for a century, such as an ion exchange, solvent extraction, selective and precipitation extraction, but there are only a few methods that specifically available to extract $\mathrm{Y}$ from e-waste. $\mathrm{Y}$ uses in many color phosphor applications such as fluorescent lamp, CRT, and LCD (Yang et al. 2013). Y is one of the common REE used in the display technology. Yttrium oxide forms the matrix of doped europium activated phosphorus. When this compound is activated, it emits bright red color (Sahoo et al. 2012).Yttrium oxide is a perfect host for the europium due to the refractory characteristic (Ronda \& Jüstel 1998). Extraction of $\mathrm{Y}$ from these abundance e-wastes are thus significant. The extraction process of REEs from LCD e-waste is a difficult task because of the very similar physical and chemical properties of the REEs present in the source. These properties of REEs are distinguishable through thermodynamic evaluation. Nakamura et al. (2007) use thermodynamic modelling to study the leaching behavior of $\mathrm{Y}$ and other rare earth elements. Thermodynamic properties such as reaction enthalpy, entropy change, Gibbs free energy and equilibrium constant are important to the understanding of the behavior of leaching process and the dissolution of the substance in the leaching reagent (Strauss 2016).These thermodynamic data are used to establish the Pourbaix diagram. Pourbaix diagrams able to provide dissolution and passivation data of the pure element relations in aqueous solutions (Pourbaix 1974). The whole REEs recovery process involves two parts, which firstly to leach out the required elements by dissolving them using specified 
reagents, and subsequently recover or extracting them individually from that reagent. Yang et al. (2013) use sulfuric, hydrochloric and nitric acids to leach out REEs from tricolour type fluorescent lamps e-waste. These reagents are potential as leaching reagents to dissolve $\mathrm{Y}$ from LCD e-waste. The solubility of $\mathrm{Y}$ in the leaching reagents able to be determined using thermodynamic data and Pourbaix diagram. Thus, the purpose of this study is mainly to identify the practicality of leaching Y from LCD ewaste using sulfuric, nitric and hydrochloric acids. Perhaps, this research may spark another branch of securing as well as recovering resources which can reduce (to some extent) the dependence on the primary resources.

\section{Material}

\subsection{METHODS AND MATERIALS}

The main materials that used in this research consisted of crashed LCD (Philip brand) that produced in 2005. The LCD was acquired from Teras Sepadu Sdn. Bhd located in Kedah, Malaysia. All the chemicals and mediums that used in the experiment were of consisting of concentrated $37 \%$ hydrochloric acid $(\mathrm{HCl}), 95 \%$ sulfuric acid $\left(\mathrm{H}_{2} \mathrm{SO}_{4}\right)$, and $68 \%$ nitric acid $\left(\mathrm{HNO}_{3}\right)$.

\section{Thermodynamic Modelling}

Thermodynamic modelling was carried out using HSC 6.0 software (Outotec Corporation). Thermodynamic properties can identify the spontaneity and feasibility of the reaction process. Reaction enthalpy, entropy change, Gibbs free energy, and equilibrium constant, calculate based on the specific chemical reaction. In this thermodynamic modelling, all the involved reactions thermodynamic data were retrieved from the species data bank. The calculation is performed by defining the available species in the sample and type of solvent used in the leaching. HSC 6.0 also used to establish Pourbaix diagram (Eh-pH diagram) of leaching process. Pourbaix diagram is critical to understand the solubility of the pure element in the aqueous solution.

\section{Leaching Y from LCD Powder}

In the leaching process part, the LCD was initially separated from plastic components such as polarizers and then crashed into powder. These powders were then subsequently sieved $(30 \mu \mathrm{m}$ mesh) to separate the large and small pieces from the powder content. The crashed, LCD powder was the main samples for leaching Y. Next, the $\mathrm{HCl}, \mathrm{HNO}_{3}$, and $\mathrm{H}_{2} \mathrm{SO}_{4}$ solutions were used as the leaching reagents, whereby 50.0 gram of LCD powder were leached with $100.0 \mathrm{ml}$ of those acidic-based leaching reagents respectively (single-stage). The mixture was then agitated for 60 minutes. Afterward, the mixture was filtrated using glass fiber filter paper to separate the remaining glass powder and solutes. Lastly, the solid residue was dried at temperature $110{ }^{\circ} \mathrm{C}$ for 48 hours. The similar steps were also applied to the two-stage leaching process, however, it was the solid residue (of the single-stage process) that utilized to be mixed with the $100 \mathrm{ml}$ of the acidic-based leaching reagents respectively. After that, the aqueous solutions were all again agitated for 60 minutes as well as settling for 15 minutes. The mixture was finally filtrated using glass fiber filter paper and dried at $110{ }^{\circ} \mathrm{C}$ for 48 hours. Figure 1 shows the flowchart scheme for the leaching process of Y from LCD e-waste. 


\section{Determination of $\mathbf{Y}$ in Filtrated Samples}

The Y content in the residue obtained from acid leaching was determined using ICP-MS Agilent Technologies model 7500 Series. Prior to ICP-MS analysis, standard solution was prepared using Agilent 5183-4681 standard. The concentration of Y was calculated from the measurement of standard solutions and residue after leaching process. The leach of $\mathrm{Y}$ was calculated from the concentration of $\mathrm{Y}$ in the raw sample and concentration of $\mathrm{Y}$ in the filtrated sample. The leach of $\mathrm{Y}$ will indicate the feasibility of leaching process and the dissolution of Y existing in the LCD e-waste.

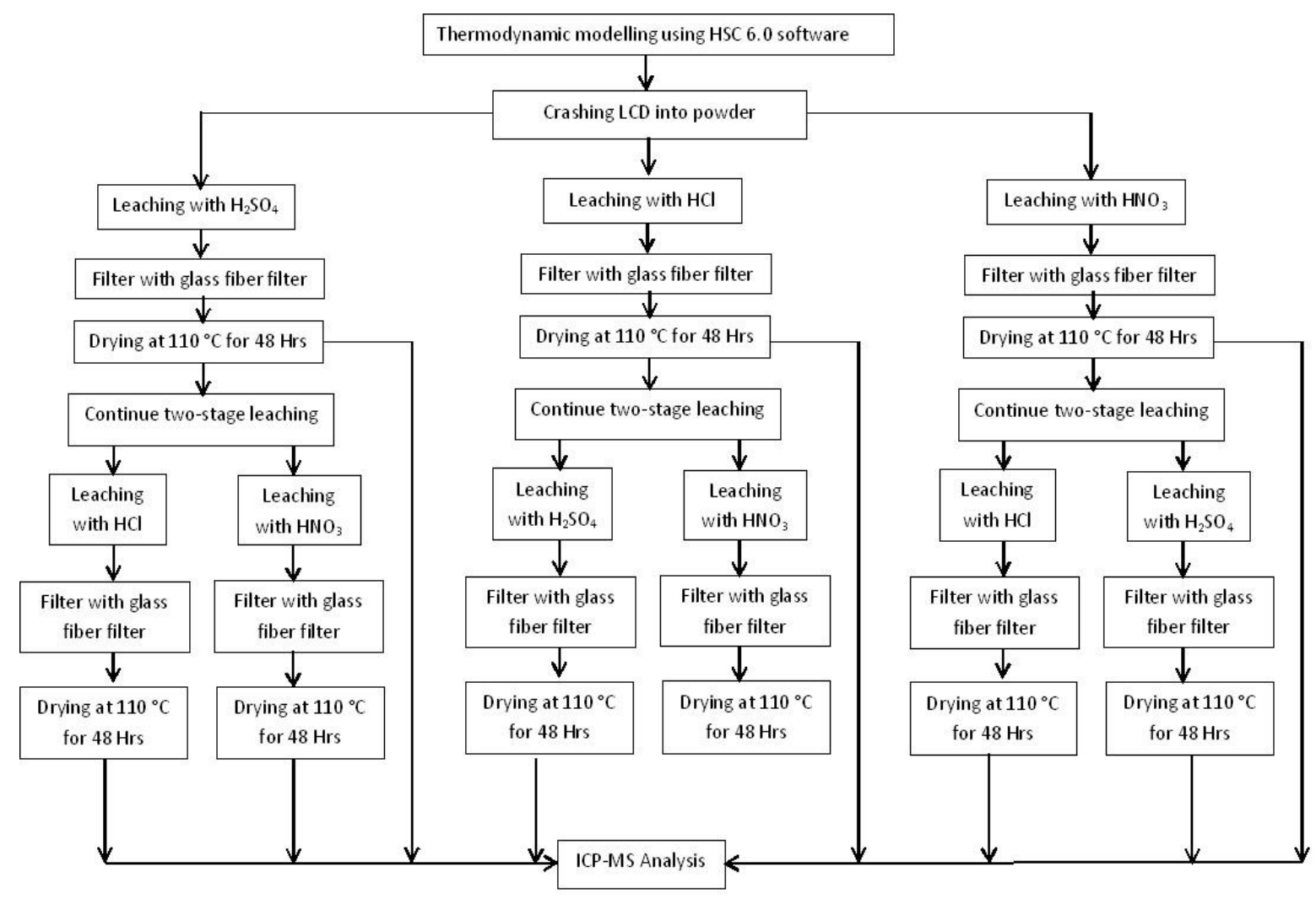

Figure 1: Proposed Acid Leaching of LCD e-waste and Recovery of Y

\subsection{RESULTS AND DISCUSSIONS}

\section{Thermodynamic Modelling}

Yttrium oxide $\left(\mathrm{Y}_{2} \mathrm{O}_{3}\right)$ is used as a color phosphor in the display technology and doped with less than five percent pure europium (Morais \& Ciminelli 2001; Havaux 2014). $\mathrm{Y}_{2} \mathrm{O}_{3}$ is used in this thermodynamic modelling and all the thermodynamic value acquire from the species database library in the HSC 6.0. The expected reaction to react with the $\mathrm{HCl}, \mathrm{H}_{2} \mathrm{SO}_{4}$, and $\mathrm{HNO}_{3}$ following the chemical reaction as depicted by the following equations:

$$
\begin{aligned}
& \mathrm{Y}_{2} \mathrm{O}_{3}+6 \mathrm{HCl} \rightarrow 2 \mathrm{YCl}_{3}+3 \mathrm{H}_{2} \mathrm{O} \\
& \mathrm{Y}_{2} \mathrm{O}_{3}+3 \mathrm{H}_{2} \mathrm{SO}_{4} \rightarrow \mathrm{Y}_{2}\left(\mathrm{SO}_{4}\right)_{3}+3 \mathrm{H}_{2} \mathrm{O}_{2}
\end{aligned}
$$




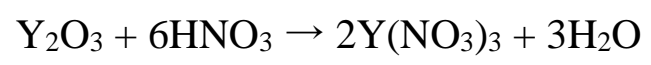

The values of reaction enthalpy, entropy change, Gibbs free energy and equilibrium constant as a result of equation 1 are presented respectively in Table 1 . The result concluded that the positive value of Gibbs free energy $(\Delta \mathrm{G}>0)$ from temperature 273.15 $\mathrm{K}$ to $343.15 \mathrm{~K}$, the reaction is not spontaneous in the forward direction. While from temperature $353.15 \mathrm{~K}$ to $373.15 \mathrm{~K}$, the negative value of Gibbs free energy $(\Delta \mathrm{G}<0)$ indicating that the decreasing level of free energy hence the reaction of $\mathrm{Y}$ should be spontaneous in the forward direction. The positive sign of reaction enthalpy signifies that the reaction is endothermic and absorbs heat. Entropy change is important to understand the reaction reversibility as a system (Connell 2017). Regarding the entropy change $(\Delta S>0)$ the reaction is irreversible, particularly from temperature $273.15 \mathrm{~K}$ and above. Equilibrium constant indicates the measure of REEs solubility in particular aqueous solution (Xuewu \& Byrne 1997). The equilibrium constant from temperature $273.15 \mathrm{~K}$ to $343.15 \mathrm{~K}$ is negative $(\log \mathrm{K}<1$ ), this particular trend demonstrates that the backward reaction is favored and thus there will be a low concentration of $\mathrm{Y}$ in the solution. While equilibrium constant from temperature $343.15 \mathrm{~K}$ to $373.15 \mathrm{~K}$ is positive $(\log K>1)$, trend demonstrates that the forward reaction is favored and thus there will be a high concentration of $\mathrm{Y}$ in the solution.

Table 1: Thermodynamic properties reaction $\mathrm{Y}_{2} \mathrm{O}_{3}$ and $\mathrm{HCl}$

\begin{tabular}{ccccc}
\hline $\mathbf{T}$ & $\mathbf{\Delta H}$ & $\Delta \mathbf{S}$ & $\boldsymbol{\Delta} \mathbf{G}$ & $\log (\mathbf{K})$ \\
$\mathbf{( K )}$ & $\mathbf{k J}$ & $\mathbf{J} / \mathbf{K}$ & $\mathbf{k J}$ & \\
\hline 273.150 & 97.807 & 282.101 & 20.752 & -3.969 \\
283.150 & 110.153 & 327.655 & 17.377 & -3.206 \\
293.150 & 105.425 & 311.240 & 14.185 & -2.528 \\
303.150 & 101.233 & 297.173 & 11.145 & -1.920 \\
313.150 & 97.304 & 284.422 & 8.237 & -1.374 \\
323.150 & 93.489 & 272.429 & 5.454 & -0.882 \\
333.150 & 89.738 & 260.995 & 2.787 & -0.437 \\
343.150 & 86.001 & 249.944 & 0.232 & -0.035 \\
353.150 & 82.213 & 239.065 & -2.212 & 0.327 \\
363.150 & 78.345 & 228.265 & -4.549 & 0.654 \\
373.150 & 74.364 & 217.450 & -6.778 & 0.949 \\
\hline
\end{tabular}

Next, the thermodynamic properties results with regard to equation 2 are shown respectively in Table 2 . The negative sign of reaction enthalpy signifies that the reaction is exothermic and release heat. The negative value of Gibbs free energy $(\Delta \mathrm{G}<0)$ from temperature $273.15 \mathrm{~K}$ and above indicates that the decreasing level of free energy, hence the reaction of $\mathrm{Y}$ should be spontaneous in the forward direction. Regarding the entropy change $(\Delta S<0)$ the reaction is reversible, particularly from temperature 273.15 $\mathrm{K}$ and above. The equilibrium constant from temperature $273.15 \mathrm{~K}$ and above is positive $(\log K>1)$, trend demonstrates that the forward reaction is favored and thus there will be a high concentration of $\mathrm{Y}$ in the solution. This also suggests that the solubility of $\mathrm{Y}$ in those specified solutions is high. 
Table 2: Thermodynamic properties reaction $\mathrm{Y}_{2} \mathrm{O}_{3}$ and $\mathrm{H}_{2} \mathrm{SO}_{4}$

\begin{tabular}{ccccc}
\hline $\mathbf{T}$ & $\mathbf{\Delta H}$ & $\Delta \mathbf{S}$ & $\boldsymbol{\Delta} \mathbf{G}$ & $\log (\mathbf{K})$ \\
$\mathbf{( K )}$ & $\mathbf{k J}$ & $\mathbf{J} / \mathbf{K}$ & $\mathbf{k J}$ & \\
\hline 273.150 & -670.284 & -773.665 & -458.958 & 87.774 \\
283.150 & -653.882 & -713.508 & -451.852 & 83.363 \\
293.150 & -688.839 & -836.668 & -443.570 & 79.044 \\
303.150 & -691.774 & -846.513 & -435.154 & 74.986 \\
313.150 & -694.779 & -856.264 & -426.640 & 71.171 \\
323.150 & -697.848 & -865.912 & -418.029 & 67.577 \\
333.150 & -700.978 & -875.448 & -409.322 & 64.183 \\
343.150 & -704.162 & -884.866 & -400.520 & 60.973 \\
353.150 & -707.397 & -894.158 & -391.625 & 57.930 \\
363.150 & -710.678 & -903.320 & -382.638 & 55.042 \\
373.150 & -714.001 & -912.347 & -373.559 & 52.296 \\
\hline
\end{tabular}

Table 3 indicates the numerical thermodynamic properties, which correspond to equation 3. From Table 3 all the properties show similar value signs with respect to enthalpy, entropy, Gibbs free energy as well as the equilibrium constant, respectively which highlights that $\mathrm{HNO}_{3}$ behaved as similar to the previous solutions.

Table 3: Thermodynamic properties reaction $\mathrm{Y}_{2} \mathrm{O}_{3}$ and $\mathrm{HNO}_{3}$

\begin{tabular}{ccccc}
\hline $\mathbf{T}$ & $\mathbf{\Delta H}$ & $\mathbf{\Delta S}$ & $\boldsymbol{\Delta} \mathbf{G}$ & $\log (\mathbf{K})$ \\
$\mathbf{( K )}$ & $\mathbf{k J}$ & $\mathbf{J} / \mathbf{K}$ & $\mathbf{k J}$ & \\
\hline 273.150 & -603.477 & -494.398 & -468.432 & 89.586 \\
283.150 & -590.837 & -447.771 & -464.050 & 85.614 \\
293.150 & -596.210 & -466.419 & -459.479 & 81.879 \\
303.150 & -601.576 & -484.419 & -454.724 & 78.358 \\
313.150 & -606.935 & -501.811 & -449.793 & 75.033 \\
323.150 & -612.286 & -518.632 & -444.690 & 71.887 \\
333.150 & -617.628 & -534.915 & -439.422 & 68.903 \\
343.150 & -622.962 & -550.688 & -433.993 & 66.068 \\
353.150 & -628.284 & -565.977 & -428.410 & 63.372 \\
363.150 & -633.594 & -580.805 & -422.675 & 60.802 \\
373.150 & -638.890 & -595.191 & -416.795 & 58.349 \\
\hline
\end{tabular}

\section{Pourbaix diagram}

Pourbaix diagram was obtained to evaluate the feasibility of acid leaching of LCD powder. Figure 2 shows the Pourbaix diagram for $\mathrm{Y}-\mathrm{Cl}-\mathrm{H}_{2} \mathrm{O}$ at $298.15 \mathrm{~K}$ that it is thermodynamic feasible to get $\mathrm{Y}$ into solution in the aqueous phase. The critical factor solubility of metal is the redox state and its ligand properties (Verink 2000). The Pourbaix diagram Figure 2 shows that $\mathrm{Y}$, dissolve in the hydrochloric acid as $\mathrm{Y}^{3+}$ at $\mathrm{pH}$ below 7 and dissolved at positive Eh value. The redox state of metals and ligands that may complex them is the critical factor in the solubility of metal. From this point of view, adding some ligands to form soluble complexes or dissolved species of REE is one way to increase the dissolution windows of REE. As noted from the diagrams, the introduction of chloride ion $\left(\mathrm{Cl}^{-}\right)$to $\mathrm{Y}$ as a ligand results in the formation of ionic and solid yttrium chloride complexes which extend its stability regions from acidic to basic conditions. These stability regions decrease as the concentration of chloride $\left(\mathrm{Cl}^{-}\right)$ decreases. As the concentration of chloride increases, other chloro-complexes appeared in acidic conditions without affecting the stability regions of RE hydroxides. Therefore, a 
strong reducing agent such as $\mathrm{H}_{2} \mathrm{SO}_{4}$ (sulfide) can improve the dissolution of $\mathrm{Y}$. The Pourbaix diagram also shows that at higher $\mathrm{pH}$ in $\mathrm{OH}$ system, $\mathrm{Y}$ is insoluble. Oxidative leaching of LCD powder is requiring dissolving Y.

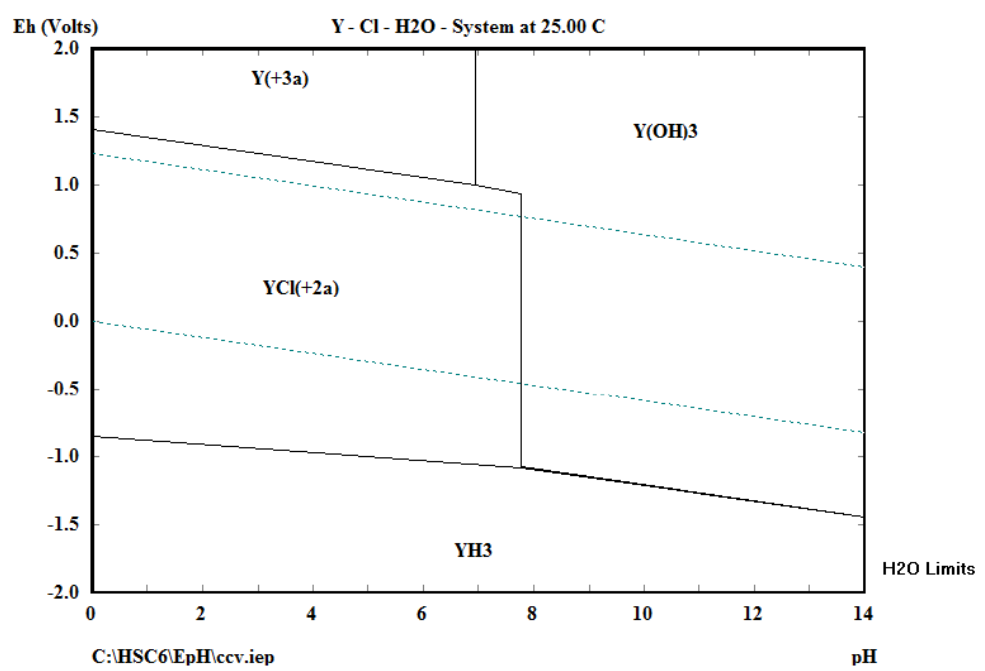

Figure 2: Pourbaix diagram $\mathrm{Y}-\mathrm{Cl}-\mathrm{H}_{2} \mathrm{O}$

\section{$Y$ concentration}

The determination of Y concentration in LCD powder was conducted before and after carrying out acid leaching processes. From Table 4, it shows that the raw sample (unleached) contains $0.00635 \mathrm{ppm}$ of initial Y. For the single-step leaching, three separate samples were leached individually using $\mathrm{HCl}, \mathrm{HNO}_{3}$, and $\mathrm{H}_{2} \mathrm{SO}_{4}$. The amount of $\mathrm{Y}$ leach out of each sample is calculated by deducting the amount of $\mathrm{Y}$ in the raw sample with treated samples as equation 4 . From Table 4, it shows that the dissolved Y concentrations in these samples are $0.00167 \mathrm{ppm}, 0.00237 \mathrm{ppm}$, and $0.00325 \mathrm{ppm}$ respectively. In this light, $\mathrm{H}_{2} \mathrm{SO}_{4}$ was identified to dissolve the highest concentration of $\mathrm{Y}$ which is $0.00325 \mathrm{ppm}$.

Leach $\mathrm{Y}=\mathrm{Y}$ in raw sample $\left(\mathrm{W}_{0}\right)-\mathrm{Y}$ in treated sample $\left(\mathrm{W}_{\mathrm{L}}\right)$

While for the two-stage leaching, there were six samples underwent alternate leaching procedures using different settings of $\mathrm{HCl}, \mathrm{HNO}_{3}$, and $\mathrm{H}_{2} \mathrm{SO}_{4}$. The sample that performed $\mathrm{H}_{2} \mathrm{SO}_{4}-\mathrm{HNO}_{3}$ and $\mathrm{HNO}_{3}-\mathrm{H}_{2} \mathrm{~S}_{4}$ leaching processes have the highest amount of dissolved $\mathrm{Y}$ which are $0.00515 \mathrm{ppm}$ and $0.00507 \mathrm{ppm}$, respectively (where both can be perceived to be almost equal in amount). This indicates that as long as the same solvent used, the solubility of $\mathrm{Y}$ are indistinguishable even though the steps were different. In other words, the combinations of $\mathrm{H}_{2} \mathrm{SO}_{4}$ and $\mathrm{HNO}_{3}$ show the most prominent data of solubility of Y from LCD powder. 
Table 4: Y concentration in the raw and leached samples

\begin{tabular}{|c|c|c|}
\hline Sample & $\begin{array}{l}\text { Y Concentration measured } \\
\text { by ICPMS in sample (ppm) }\end{array}$ & $\begin{array}{c}\text { Calculation amount } \\
\left(\mathbf{W}_{0}-W_{L}\right)(\mathbf{p p m})\end{array}$ \\
\hline Raw $\left(\mathrm{W}_{0}\right)$ & 0.00635 & 0.0000 \\
\hline $\mathrm{HCl}\left(\mathrm{W}_{\mathrm{L}}\right)$ & 0.00468 & 0.00167 \\
\hline $\mathrm{HNO}_{3}\left(\mathrm{~W}_{\mathrm{L}}\right)$ & 0.00398 & 0.00237 \\
\hline $\mathrm{H}_{2} \mathrm{SO}_{4}\left(\mathrm{~W}_{\mathrm{L}}\right)$ & 0.00310 & 0.00325 \\
\hline $\mathrm{HCl}-\mathrm{HNO}_{3}\left(\mathrm{~W}_{\mathrm{L}}\right)$ & 0.00150 & 0.00485 \\
\hline $\mathrm{HCl}-\mathrm{H}_{2} \mathrm{SO}_{4}\left(\mathrm{~W}_{\mathrm{L}}\right)$ & 0.00180 & 0.00455 \\
\hline $\mathrm{HNO}_{3}-\mathrm{HCl}\left(\mathrm{W}_{\mathrm{L}}\right)$ & 0.00155 & 0.00480 \\
\hline $\mathrm{HNO}_{3}-\mathrm{H}_{2} \mathrm{SO}_{4}\left(\mathrm{~W}_{\mathrm{L}}\right)$ & 0.00128 & 0.00507 \\
\hline $\mathrm{H}_{2} \mathrm{SO}_{4}-\mathrm{HNO}_{3}\left(\mathrm{~W}_{\mathrm{L}}\right)$ & 0.00120 & 0.00515 \\
\hline $\mathrm{H}_{2} \mathrm{SO}_{4}-\mathrm{HCl}\left(\mathrm{W}_{\mathrm{L}}\right)$ & 0.00190 & 0.00445 \\
\hline
\end{tabular}

\subsection{CONCLUSION}

Thermodynamic modelling of the anticipated possible reaction that occurred during the leaching process on the LCD, e-waste in order to leach out Y was studied. The corresponding thermodynamic properties include enthalpy, entropy change, Gibbs free energy and equilibrium constant. The general finding suggests that the reaction with hydrochloric acid is endothermic and absorb heat as well as the transition from spontaneous backward to spontaneous forward as temperature increases. Also, as the temperature increase, the equilibrium constant value increase indicates the solubility increase as the temperature increase. The leaching reactions with $\mathrm{H}_{2} \mathrm{SO}_{4}$ and $\mathrm{HNO}_{3}$ suggest that the reactions are exothermic and release heat as well as from temperature $273.15 \mathrm{~K}$ and above the reactions are spontaneous in the forward direction. The equilibrium constant value indicates that the solubility of $\mathrm{Y}$ in the $\mathrm{H}_{2} \mathrm{SO}_{4}$ and $\mathrm{HNO}_{3}$ decreases as the temperature increase nevertheless, the solubility of $\mathrm{Y}$ in those reagents remain high due to the positive equilibrium constant. Thermodynamic data revealed that the reactions of $\mathrm{Y}$ with $\mathrm{HNO}_{3}$ as well as $\mathrm{H}_{2} \mathrm{SO}_{4}$ are significant due to the reversible reaction in contra to $\mathrm{HCl}$. The ICP-MS data support these findings, which specifically demonstrated that the samples using both $\mathrm{HNO}_{3}$ and $\mathrm{H}_{2} \mathrm{SO}_{4}$ were concentrated with a higher amount of $\mathrm{Y}$ reduction. Meanwhile, the Pourbaix diagram signified that the leaching process should be feasibly operated at $\mathrm{pH}$ below 7. ICP-MS analysis has shown that $\mathrm{Y}$ element can be extractable feasibly either by the single or two-stage process. In addition, both $\mathrm{HNO}_{3}$ and $\mathrm{H}_{2} \mathrm{SO}_{4}$ were identified as the best option to be utilized as the leaching reagent relative to $\mathrm{HCl}$. 


\section{ACKNOWLEDGEMENT}

The author wishes to thank Rare Earth Research Centre (RERC), UMP for the fund and technical assistance. The author acknowledges the facilities and the technical assistance of the Central Lab, UMP for ICP-MS

\section{REFERENCES.}

Binnemans, K. et al., 2013. Recycling of rare earths: A critical review. Journal of Cleaner Production, 51, pp.1-22. Available at: http://dx.doi.org/10.1016/j.jclepro.2012.12.037.

Connell, J.P.O., 2017. Chemical process systems analysis using thermodynamic balance equations with entropy generation. Computers and Chemical Engineering, 107, pp.3-15. Available at: https://doi.org/10.1016/j.compchemeng.2017.03.003.

Deqian, L.I., 2017. A review on yttrium solvent extraction chemistry and separation process. Journal of Rare Earths, 35(2), pp.107-119. Available at: http://dx.doi.org/10.1016/S1002-0721(17)60888-3.

Eduafo, P.M., 2016. Investigation of Recovery and Recycling Of Rare Earth Elements from Waste Fluorescent Lamp Phosphors. Colorado School of Mines.

Gupta, C.K.K. \& Krishnamurthy, N., 2005. Extractive metallurgy of rare earths, Available at: http://www.maneyonline.com/doi/abs/10.1179/imr.1992.37.1.197\%5Cnhttp://www.tandfonline.co m/doi/full/10.1179/imr.1992.37.1.197.

Haque, N. et al., 2014. Rare Earth Elements: Overview of Mining, Mineralogy, Uses, Sustainability and Environmental Impact. , pp.614-635.

Nakamura, T., Nishihama, S. \& Yoshizuka, K., 2007. Separation and recovery process. for rare earth metals from fluorescence material wastes using solvent extraction. Solvent Extraction Research and Development, 14, pp.105-113.

Park, H. \& Rhee, S., 2016. Estimation of retorted phosphor powder from spent fluorescent lamps by thermal process. Waste Management, 50, pp.257-263. Available at: http://dx.doi.org/10.1016/j.wasman.2016.01.032.

Paulick, H. \& Machacek, E., 2017. The global rare earth element exploration boom: An analysis of resources outside of China and discussion of development perspectives. Resources Policy, 52(February), pp.134-153. Available at: http://dx.doi.org/10.1016/j.resourpol.2017.02.002.

Pourbaix, M., 1974. Atlas of Electrochemical Equilibria in Aqueous solutions 2nd ed., Pergamon, New York: National Association of Corrosion Engineers.

Ronda, C. \& Jüstel, T., 1998. Rare Earth Phosphors Fundamentals and Applications. Journal of Alloys and Compounds, 275-277, pp.669-676.

Sahoo, S. et al., 2012. Ferroelectric properties and ac conductivity studies of yttrium modified $\mathrm{Pb}(\mathrm{Fe} 0.5 \mathrm{Nb} 0.5) \mathrm{O} 3$ ceramics. Solid State Sciences, 14(6), pp.668-672. Available at: http://linkinghub.elsevier.com/retrieve/pii/S1293255812000854.

Strauss, M.L., 2016. The Recovery of Rare Earth Oxides from Waste Fluorescent Lamps. Colorado School of Mines.

Vijayalakshmi, R. et al., 2001. Processing of xenotime concentrate by sulphuric acid digestion and selective thorium precipitation for separation of rare earths. Hydrometallurgy, 61(2), pp.75-80.

Xuewu, L. \& Byrne, R.H., 1997. Rare earth and yttrium phosphate solubilities in aqueous solution. Geochirnica et Cosmochimica Acta, 61(8), pp.1625-1633.

Yang, F. et al., 2013. Selective extraction and recovery of rare earth metals from phosphor powders in waste fluorescent lamps using an ionic liquid system. Journal of Hazardous Materials, 254-255(1), pp.79-88. Available at: http://dx.doi.org/10.1016/j.jhazmat.2013.03.026. 